\title{
DNA recovery from used malaria RDT to detect Plasmodium species and to assess Plasmodium falciparum genetic diversity: A pilot study in Madagascar
}

Voahangy Hanitriniaina Isabelle ANDRIANARANJAKA ( $\nabla$ fararanontsoa@gmail.com ) Universite d'Antananarivo Faculte des Sciences https://orcid.org/0000-0002-4881-8958

Elisabeth Ravaoarisoa

Universite d'Antananarivo Faculte des Sciences

Tovonanahary Angelo Rakotomanga

Universite d'Antananarivo Faculte des Sciences

Fanomezantsoa Ralinoro

Universite d'Antananarivo Faculte des Sciences

Danielle A Doll Rakoto

Universite d'Antananarivo Faculte des Sciences

Hanitra Randrianarivo

Universite d'Antananarivo Faculte des Sciences

Victor Jeannoda

Universite d'Antananarivo Faculte des Sciences

Arsène Ratsimbasoa

Universite de Fianarantsoa

\section{Research Article}

Keywords: RDT, molecular biology, Plasmodium falciparum, genetic diversity, multiplicity of infection, Madagascar.

Posted Date: February 21st, 2022

DOI: https://doi.org/10.21203/rs.3.rs-1250809/v1

License: (9) (1) This work is licensed under a Creative Commons Attribution 4.0 International License. Read Full License 


\section{Abstract}

Background: Rapid diagnostic tests (mRDT) are widely used for malaria diagnosis in Madagascar, where Plasmodium falciparum is the predominant species. Molecular diagnosis is essential for malaria surveillance, but requires additional blood samples for DNA extraction. Used mRDTs is an attractive alternative that can be used as a source of DNA. P. falciparum genetic diversity and multiplicity of infection, usually determined by the genotyping of polymorphic regions of merozoite surface proteins 1 and 2 genes ( $m s p 1, m s p 2)$, and the repeated region RII of the glutamate-rich protein gene (glurp) have been associated with malaria transmission levels and subsequently with the impact of the deployed control strategies.

Thus, the study aims using mRDT as DNA source to detect Plasmodium species, to characterize $P$. falciparum genetic diversity and determine the multiplicity of infection.

Methods: A pilot study was conducted in two sites with different epidemiological patterns: Ankazomborona (low transmission area) and Matanga (high transmission area). On May 2018, used mRDT (SD BIOLINE Malaria Ag P.f/Pan, 05FK63) were collected as DNA source. Plasmodium DNA was extracted by simple elution with nuclease free water. Nested-PCR were performed to confirm Plasmodium species and to analyze $P$. falciparum $m s p 1, m s p 2$ and glurp genes polymorphisms.

Results: Amongst the 170 obtained samples ( $\mathrm{N}=74$ from Ankazomborona and $\mathrm{N}=96$ from Matanga), Plasmodium positivity rate was $23.5 \%$ (40/170) [95\% Cl: $17.5-30.8 \%$ ] by nested-PCR with $92.2 \%(37 / 40)$ positive to $P$. falciparum, $5 \%(2 / 40)$ to $P$. vivax and $2.5 \%$ (1/40) to $P$. falciparum/P. vivax mixed infection. Results showed high polymorphisms in $P$. falciparum msp1, msp2 and glurp genes. Multiple infection rate was $28.6 \%$ [ $95 \% \mathrm{Cl}: 12.2-52.3 \%]$. The mean of $\mathrm{MOI}$ was $1.79 \pm 0.74$.

Conclusion: This pilot study highlighted that malaria diagnosis and molecular analysis are possible by using used malaria RDT. A large-scale study needs to be conducted to assess more comprehensively malaria parasites transmission levels and provide new data for guiding the implementation of local strategies for malaria control and elimination.

Trial registration: retrospectively registered

\section{Background}

Despite the deployment of considerable efforts and various strategies to control and eliminate malaria, this disease remains one of the main cause of morbidity and mortality worldwide [1]. In 2020, 241 million cases were reported leading to 627,000 deaths [2]. Sub-Saharan Africa including Madagascar still remains the most affected region [2]. Among the five Plasmodium species infecting humans, $P$. falciparum is the most prevalent malaria species in Sub-Saharan Africa and the most virulent species leading severe malaria [3]. 
Rapid Diagnostic Tests for malaria (mRDT) are commonly used for malaria diagnosis in field by community health workers to promptly manage malaria cases. Malaria molecular diagnosis are essential for epidemiological surveillance, but requires to collect additional blood samples for DNA extraction. Used mRDTs is an attractive alternative that can be used as a source of DNA [4-6].

P. falciparum genotyping remains an important tool for studying types and numbers of parasite clones present in an infection. Currently, this approach is mainly used to investigate the genetic diversity of parasites in human infections and subsequently estimate the malaria transmission intensity [1, 7-10]. Moreover, numerous studies have demonstrated an association between high multiplicity of infection (MOI) and malaria severity, especially in high malaria transmission areas [11]. Usually, P. falciparum genetic diversity is determined by the genotyping of the polymorphic regions of the block 2 of merozoite surface protein-1 (msp1), block 3 of merozoite surface protein-2 ( $m s p 2$ ) and the RIl repeated region of the glutamic rich protein genes (g/urp) [12-15].

In Madagascar, four to eight malaria ecozones are described according to their different epidemiological profile that range from low to high transmission $[16,17]$. Regular molecular and epidemiological monitoring over time and space of the genetic diversity of $P$. falciparum populations in association with malaria phenotypes (uncomplicated malaria, severe malaria and asymptomatic malaria cases) is crucial to evaluate the impact of malaria control interventions and to guide the deployment of local tailored strategies for elimination $[1,11,18,19]$.

Hence, this study aims to valorize blood samples collected onto mRDT as DNA source for detecting Plasmodium infections, assessing the genetic diversity of $P$. falciparum populations and estimating the $\mathrm{MOI}$ in $P$. falciparum isolates collected from symptomatic patients seen in health centres in two sites with different epidemiological patterns: Ankazomborona, located in a low transmission area and Matanga in a high transmission area.

\section{Materials And Methods}

Study sites and sample collection. The study was conducted on May 2018 in two sites. In Ankazomborona, district region of Marovoay, located on the west coast of Madagascar ( $16^{\circ} 07^{\prime} 00^{\prime \prime} \mathrm{S}$ and $\left.46^{\circ} 45^{\prime} 00^{\prime \prime} \mathrm{E}\right)$, a seasonal, endemic and low transmission area and in Matanga, district region of Vangaindrano, located on the east coast of Madagascar ( $23^{\circ} 31^{\prime} 00^{\prime \prime} \mathrm{S}$ and $47^{\circ} 33^{\prime} 00^{\prime \prime} \mathrm{E}$ ), a perennial endemic and high transmission area (Figure1). P. falciparum-positive mRDT were collected. They were obtained from children aged 6 months to 15 years suffering to uncomplicated malaria. These mRDT containing blood samples were conserved at room temperature before DNA extraction.

DNA extraction. To improve the protocol aiming at extracting parasite DNA from mRDT, EDTA tubes containing whole blood infected by $P$. falciparum and $P$. vivax were used. Blood smears were read to identify Plasmodium species and estimate the parasite density (parasites $/ \mu \mathrm{L}$ ). Blood samples were then diluted with non-infected blood to obtain aliquots containing parasitemia ranging from 1500 parasites/ $\mu \mathrm{L}$ to 5 parasites/ $\mu \mathrm{L}$. Four mRDT were tested for each dilution. The cassettes of mRDT were opened 
laterally and the strips were taken out and cut for DNA extraction. For each parasite densities, four different parts of the strip were used to estimate the best yield of DNA extract: (A) distal part, (B) central part, (C) proximal part and (D) all parts (Figure 2).

Two methods of DNA extraction were applied: the Instagene Matrix@ method (BioRad ${ }^{\mathrm{TM}}$ ), according to the manufacturer's instructions and a simple elution method in water as previously described [4].

P. falciparum and P. vivax detection by nested-PCR. Nested-PCR [20] was performed to detect $P$. falciparum and $P$. vivax DNA and estimate which DNA extraction method and which part of mRDT strip provide the more reliable results. Nested-PCR assays showed that all parts of mRDT strip and simple elution method in water were the best approaches (see Results section). These methods were then selected for all further experiments.

Plasmodium falciparum msp1, msp2 and glurp genotyping. The polymorphic region of $m s p 1, m s p 2$ and glurp were genotyped using nested-PCR. Primers targeting the block 2 region of $m s p 1$, the block 3 region of $m s p 2$, and the RII repeated region of glurp were used for primary PCR (Table 1). All PCR reactions were carried out in a total volume of $25 \mu \mathrm{L}$, containing $200 \mathrm{nM}$ dNTP mix, $2 \mathrm{mM} \mathrm{MgCl}_{2}$, 200nM each of forward and reverse primers for both $m s p 1, m s p 2$ and glurp, $0.5 \mathrm{U}$ of Taq DNA Polymerase (Bioline) and $3 \mu \mathrm{L}$ of extracted DNA, used as template. PCR amplification of $m s p 1, m s p 2$ and glurp genes comprised an initial step of $94^{\circ} \mathrm{C}$ for 5 min followed by 30 cycles of $94^{\circ} \mathrm{C}$ for $30 \mathrm{~s}, 55^{\circ} \mathrm{C}$ for $30 \mathrm{~s}, 72^{\circ} \mathrm{C}$ for $1 \min 30 \mathrm{~s}$, and a final extension of $72^{\circ} \mathrm{C}$ for $5 \mathrm{~min}$. 
Table 1

Primary and secondary PCR primers

\begin{tabular}{|c|c|c|c|c|}
\hline Gene & $\begin{array}{l}\text { Allelic } \\
\text { type }\end{array}$ & PCR round & Primer sequence $\left(5^{\prime}-3^{\prime}\right)$ & $\begin{array}{l}\text { Fragment size } \\
\text { (bp) }\end{array}$ \\
\hline \multirow[t]{8}{*}{ Msp1 } & & \multirow{2}{*}{$\begin{array}{l}\text { Primary } \\
\text { PCR }\end{array}$} & CACATGAAAGTTATCAAGAACTTGTC & \multirow[t]{2}{*}{633} \\
\hline & & & GTACCGCTAATTCATATTCTATTGCTAG & \\
\hline & \multirow[t]{2}{*}{ MAD20 } & \multirow[t]{2}{*}{ Nested PCR } & GAACAAGTSGAACAGCTGTTA & \multirow[t]{2}{*}{$120-250$} \\
\hline & & & TGAATTATCTGAAGGATTTGTACGCCT & \\
\hline & \multirow[t]{2}{*}{$\mathrm{K} 1$} & \multirow[t]{2}{*}{ Nested PCR } & GAAATTACTACAAAAGGTGCCAAGTG & \multirow[t]{2}{*}{$160-300$} \\
\hline & & & AGATGAAGTATTTGAACGAGCTAAAGT & \\
\hline & \multirow[t]{2}{*}{$\mathrm{RO33}$} & \multirow[t]{2}{*}{ Nested PCR } & GCAAATACTCAAGTTGTTGCAAAGC & \multirow[t]{2}{*}{$100-160$} \\
\hline & & & AGGATTTGCAGCAYCCTGGAGATCT & \\
\hline \multirow[t]{6}{*}{ Msp2 } & & \multirow{2}{*}{$\begin{array}{l}\text { Primary } \\
\text { PCR }\end{array}$} & ATGAAGGTAATTAAAACATTGTCTATTAAT & \multirow[t]{2}{*}{811} \\
\hline & & & ATATGGCAAAAGATAAAACAAGTGTTGCTG & \\
\hline & \multirow[t]{2}{*}{$3 \mathrm{D} 7$} & \multirow[t]{2}{*}{ Nested PCR } & GCAGAAAGTAAKGCCTYTCTACTGGTGCT & \multirow[t]{2}{*}{$150-350$} \\
\hline & & & AGATGAAGTATTTGAACGAGGTAAAGTG & \\
\hline & \multirow[t]{2}{*}{ FC27 } & \multirow[t]{2}{*}{ Nested PCR } & GCAAATGAAGGTTCTAATACTAATAG & \multirow[t]{2}{*}{$300-600$} \\
\hline & & & GCTTTGGGTCCTTCTTCAGTTGATTC & \\
\hline \multirow[t]{4}{*}{ Glurp } & & \multirow[t]{2}{*}{$\begin{array}{l}\text { Primary } \\
\text { PCR }\end{array}$} & $\begin{array}{l}\text { ATG AAT TYG AAG ATG TTC ACA CTG } \\
\text { AAC }\end{array}$ & \multirow[t]{2}{*}{1200} \\
\hline & & & $\begin{array}{l}\text { ATG AAT TYG AAG ATG TTC ACA CTG } \\
\text { AAC }\end{array}$ & \\
\hline & & \multirow[t]{2}{*}{ Nested PCR } & CTG AAC CAA ATCA AAA TAA CG & \multirow[t]{2}{*}{$600-1000$} \\
\hline & & & TTC TTC TGG TTT TAT AGT TTC & \\
\hline
\end{tabular}

For the nested-PCR, specific primers to allelic families of msp1 (MAD20, K1, and R033), and msp2 (3D7 and FC27) were used. For glurp amplification, inner primers were used to amplify generated amplicons (Table 1). This secondary reaction contained the same reagents as the primary reaction except primers (Table 1 ) and $2 \mu \mathrm{L}$ of the primary PCR product was used as DNA template. The cycling profile for the secondary PCR was similar to the primary PCR for glurp while for $m s p 1$ and $m s p 2$ the annealing temperature was increased from $55^{\circ} \mathrm{C}$ to $60^{\circ} \mathrm{C}$. DNA from non-infected blood and from reference $P$. falciparum strains (3D7, Dd2 and 7G8) were included in each set of PCR reactions as a negative and positive controls. 
Eight microliters of nested PCR products were loaded on $2 \%$ agarose gel stained with ethidium bromide and separated by electrophoresis for an average of $60 \mathrm{~min}$ at $120 \mathrm{~V}$. After electrophoresis, the gels were visualized under UV trans-illumination using Image Lab gel doc system and then analyzed to estimate the bands sizes. PCR products size were estimated by Image Lab software using 100bp DNA ladder marker.

Polyclonal infection was defined by the presence of more than one allele for a given gene [21, 22]. Multiplicity of infection (MOI) was defined by the number of genotypes per infection [23].

\section{Results}

Optimization of DNA extraction. Out of 16 mRDT samples (8 tested with $P$. falciparum infected bloods and 8 by $P$. vivax infected bloods), DNA extracted from all parts of mRDT strip and simple elution method in water gave successful results by PCR amplification (Figure 3 ).

P. falciparum and P. vivax infections by nested PCR. Out of 170 samples of used mRDT (74 from Ankazomborona and 96 from Matanga) analyzed, nested-PCR allowed to detect 40 positives samples $(23.5 \%, 95 \% \mathrm{Cl}: 17.5-30.8 \%)$ of which 37 were P. falciparum $(92.5 \%, 95 \% \mathrm{Cl}: 78.5-98.0 \%), 2$ P. vivax (5\%, $95 \% \mathrm{Cl}: 0.9-18.2 \%)$ and 1 P. falciparum/ P. vivax mixed infection (2.5\%, 95\% Cl: $0.1-14.7 \%)$ (Table 2).

Table 2

Positivity of P. falciparum and P. vivax by nested PCR

\begin{tabular}{|lllllll|}
\hline & \multicolumn{2}{l}{ Ankazomborona $(\mathbf{n = 7 4 )}$} & \multicolumn{2}{c|}{ Matanga $(\mathbf{n = 9 6 )}$} & \multicolumn{2}{c|}{ Total $(\mathbf{N}=170)$} \\
\hline & $\mathbf{n}$ & $\%$ & $\mathbf{N}$ & $\%$ & $\mathbf{n}$ & $\%$ \\
\hline P. falciparum & 16 & 21.6 & 21 & 21.9 & 37 & 21.8 \\
\hline P. vivax & 2 & 2.7 & & & 2 & 1.2 \\
\hline P. falciparum + P. vivax & 1 & 1.4 & & & 1 & 0.6 \\
\hline Negative & 55 & 74.3 & 75 & 76.5 & 130 & 76.5 \\
\hline
\end{tabular}

Frequency of msp1 and msp2 allelic families. Out of all 38 P. falciparum positive samples, 21 were successfully amplified for $m s p 1$ (55.3\%, 95\%Cl: 38.5 - 71.0\%) and 9 for $m s p 2(23.7 \%, 95 \% \mathrm{Cl}: 12.0-$ $40.6 \%$ ). For $m s p 1$, MAD20 was the most frequent allelic family and detected in $52.4 \%$ (95\% Cl: $30.3-$ $73.6 \%)$ of the samples, followed by R033 (47.6\%; 95\%Cl: $26.4-69.7 \%)$ and K1 (28.6\%; 95\%Cl: $12.2-$ $52.3 \%$ ). A total of $28.6 \%$ of the positive samples for $m s p 1$ contained polyclonal infection with MAD20/K1, MAD20/R033 and K1/R033. For $m s p 2$, all positive samples (9/9) belonged to the FC27 allelic family and were classified as monoclonal infection. None of the 3D7 allelic family was detected.

Genetic diversity, allelic frequency and multiplicity of infection. Generated alleles were classified according to their fragment sizes for $m s p 1, m s p 2$ and glurp. Allelic frequency for an allele was defined as being its proportion compared to the total number of all detected alleles in the whole isolates. $P$. falciparum isolates in both sites were highly polymorphic, since almost alleles detected were once. 
For msp 1 gene, 14 different alleles were observed: 4 alleles for MAD20 (size range 150-250 bp), 1 allele for R033 (size range 120-150 bp) and for 6 alleles for K1 (size range 140-300 bp) (Table 2). Only one sample from Matanga presented polyclonal infection for MAD20 allelic family (Table 3).

Table 3

Alleles distribution for Msp1

\begin{tabular}{|c|c|c|c|c|}
\hline Allele & Fragment size (bp) & Ankazomborona n (\%) & Matanga n (\%) & Total n (\%) \\
\hline \multicolumn{5}{|c|}{ MAD20 allelic family } \\
\hline MAD20-A & 150 & $1(9)$ & $0(0)$ & $1(9)$ \\
\hline MAD20-B & 200 & $5(46)$ & $2(18)$ & $7(64)$ \\
\hline MAD20-C & 250 & $0(0)$ & $2(18)$ & $2(18)$ \\
\hline MAD20-D & $200+250$ & $0(0)$ & $1(9)$ & $1(9)$ \\
\hline \multicolumn{2}{|c|}{ Total for MAD20 } & $6(55)$ & $5(45)$ & $11(100)$ \\
\hline \multicolumn{5}{|c|}{ R033 allelic family } \\
\hline R033 & $120-150$ & $5(50)$ & $5(50)$ & $10(100)$ \\
\hline \multicolumn{2}{|c|}{ Total for R033 } & $5(50)$ & $5(50)$ & $10(100)$ \\
\hline \multicolumn{5}{|c|}{ K1 allelic family } \\
\hline K1-A & 140 & $0(0)$ & $1(\approx 17)$ & $1(\approx 17)$ \\
\hline $\mathrm{K} 1-\mathrm{B}$ & 160 & $1(\approx 17)$ & $0(0)$ & $1(\approx 17)$ \\
\hline $\mathrm{K} 1-\mathrm{C}$ & 180 & $0(0)$ & $1(\approx 17)$ & $1(\approx 17)$ \\
\hline K1-D & 220 & $1(\approx 17)$ & $0(0)$ & $1(\approx 17)$ \\
\hline K1-E & 240 & $0(0)$ & $1(\approx 17)$ & $1(\approx 17)$ \\
\hline K1-F & 300 & $0(0)$ & $1(\approx 17)$ & $1(\approx 17)$ \\
\hline \multicolumn{2}{|c|}{ Total for $\mathrm{K} 1$} & $2(33.3)$ & $4(67.7)$ & $6(100)$ \\
\hline
\end{tabular}

For $m s p 2$ gene, only the FC27 allelic family was observed but the genetic diversity was high: 6 different alleles were detected among the 9 positive samples (Table 4). 
Table 4

Allele distribution for Msp2 (FC27 allelic family)

\begin{tabular}{|lllll|}
\hline Allele & Fragment size (bp) & Ankazomborona $\mathbf{n}(\%)$ & Matanga $\mathbf{n}(\%)$ & Total $\mathbf{n}(\%)$ \\
\hline FC27-A & 420 & $1(11)$ & $0(0)$ & $1(11)$ \\
\hline FC27-B & 440 & $1(11)$ & $2(22)$ & $3(33)$ \\
\hline FC27-C & 460 & $2(22)$ & $0(0)$ & $2(22)$ \\
\hline FC27-D & 500 & $1(11)$ & $0(0)$ & $1(11)$ \\
\hline FC27-E & 520 & $0(0)$ & $1(11)$ & $1(11)$ \\
\hline FC27-F & 540 & $0(0)$ & $1(11)$ & $1(11)$ \\
\hline Total & & $\mathbf{5 ( 5 5 . 6 )}$ & $\mathbf{4 ( 4 4 . 4 )}$ & $9(100)$ \\
\hline
\end{tabular}

Table 5

Allele distribution for Glurp

\begin{tabular}{|lllll|}
\hline Allele & Fragment size (bp) & Ankazomborona $\mathbf{n}(\%)$ & Matanga $\mathbf{n}(\%)$ & Total $\mathbf{n}(\%)$ \\
\hline Glurp-A & $600 \mathrm{pb}$ & $2(10)$ & $2(10)$ & $4(20)$ \\
\hline Glurp-B & $650 \mathrm{pb}$ & $1(5)$ & $1(5)$ & $2(10)$ \\
\hline Glurp-C & $700 \mathrm{pb}$ & $1(5)$ & $3(15)$ & $4(20)$ \\
\hline Glurp-D & $750 \mathrm{pb}$ & $3(15)$ & $2(10)$ & $5(25)$ \\
\hline Glurp-E & $800 \mathrm{pb}$ & $1(5)$ & $1(5)$ & $2(10)$ \\
\hline Glurp-F & $850 \mathrm{pb}$ & $1(5)$ & $0(0)$ & $1(5)$ \\
\hline Glurp-G & $900 \mathrm{pb}$ & $1(5)$ & $0(0)$ & $1(5)$ \\
\hline Glurp-H & $950 \mathrm{pb}$ & $0(0)$ & $1(5)$ & $1(5)$ \\
\hline Total & & $10(50)$ & $10(50)$ & $\mathbf{2 0}(100)$ \\
\hline
\end{tabular}

For glurp gene, out of the 38 P. falciparum positive samples, 20 (52.6\%; 95\%IC: $36.0-68.7 \%)$ were successfully amplified. As for $m s p 1$ and $m s p 2$ genes, a high proportion of different alleles $(\mathrm{N}=8)$ was observed (Figure 4A and 4B, Table 4).

The mean value of $\mathrm{MOI}$ was $1.79 \pm 0.74$, similar in both sites $(1.79 \pm 0.80$ in Ankazomborona and $1.79 \pm$ 0.70 in Matanga). No significant difference in MOI was also observed between $m s p 1$ (1.33 \pm 0.48$), m s p 2$ $(1.0 \pm 0)$ and glurp $(1.0 \pm 0)$ genes.

\section{Discussion}


Compared methods for DNA extraction showed that simple water elution method gave higher successful result. Thus, this method was adopted in the study. One hundred seventy used mRDT samples were analyzed. The Plasmodium positivity rate was $23.5 \%$ (95\% Cl: $17.5-30.8 \%)$ including $92.2 \% P$. falciparum positive, $5 \%$ P. vivax positive and $2.5 \%$ P. falciparum/P. vivax mixed positive samples. Although this low positivity rate, this study highlighted the opportunity using used mRDT for malaria diagnosis and molecular analysis [4]. The main advantage is that no other consumable, nor reagent for blood sampling are needed and mRDT are widely available in public health facilities since 2008 in Madagascar [24]. However, data presented here suggest that DNA extraction method should be improved for increasing the yield of parasite DNA [5]. Here, the laboratory analysis were carried out 8 months after the collection of used mRDT that were stored two months in field. We suspect that the storage of used mRDT in the field conditions has likely affected the DNA integrity. Conducting a study with large samples, about the impact of storage duration and conditions of used mRDT on the quality of the DNA extract is necessary.

Out of 38 confirmed $P$. falciparum samples, 21 were successfully amplified for $m s p 1$ (55.3\%, 95\%Cl: 38.5 - 71.0\%). The most frequent allelic family was MAD20 (52.4\%), followed by RO33 (47.6\%) and K1 (28.6\%), similar to those found in Equatorial Guinea, Myanmar and Senegal [22, 25, 26], but in contrast to those observed in Congo DR and Yemen where the K1 allelic family predominate about 40 to $60 \%[27,28]$.

For the $m s p 2$, only 9 of 38 confirmed samples were successfully amplified and belonged to the FC27 allelic family, concordant with data observed by Rakotomanjaka in the same locality (Matanga) in 2016 [29]. This is not the case in all localities in Madagascar, since several studies reported higher frequency of 3D7 allelic (up to 48\%) such as in Andapa, Mahasolo and Saharevo [30, 31].

Analysis based on the PCR product fragments showed 4 distinct alleles for MAD 20 allelic family (11 samples), 1 allele for RO33 (10 samples) and 6 alleles for K1 ( 6 samples). The K1 allelic family was found at low frequency (28.6\%) compared to MAD20 and RO33, but this allelic family was more polymorphic ( 6 distinct alleles for 6 samples). For FC27 allelic family of $m s p 2$, out of the 9 positive samples, 6 distinct alleles were detected. Regarding to glurp gene, 8 distinct alleles were observed in the 20 positive samples. Polymorphism analysis showed high genetic diversity of $P$. falciparum populations in Ankazomborona and Matanga. Majority of alleles detected during in this study were single with a high polymorphism level. No significant difference of polymorphism level was detected in two study sites.

Parasite genetic diversity is one of key elements to consider for strategies implementation to fight against malaria [28]. It has an impact on parasite transmission and control strategies, and it varies according to transmission in endemic areas [7-10]. According to the results, it seems, transmission intensity is similar in Ankazomborona and in Matanga. Nevertheless, a study on large samples is crucial before giving final conclusion.

This study showed $28.6 \%$ multiple infection for $P$. falciparum $m s p 1$ gene not for $m s p 2$ and glurp. These results indicate that polyclonal infection frequency is low compared to those found in other countries [32, 33]. The $\mathrm{MOI}$ average value was $1.79 \pm 0.74$, a lower value than in other northwestern Ethiopia (2.6), in 
Republic of Congo (2.64), and in Equatorial Guinea (5.5) [23, 25, 28]. MOI for Ankazomborona and Matanga did not differ significantly. Thus, hypothesis concerning the link between the high level of $\mathrm{MOI}$ and malaria severity, particularly in areas with high transmission rate [11], is not verified during this study due to the limited number of samples. Despite this, we can deduce that $P$. falciparum populations circulating in Madagascar showed a high level of genetic polymorphism. That high polymorphism reflects transmission intensity. Consequently, it would be interesting to increase samples number in order to continue genetic diversity study over time and space for carrying out a cartographic study about Plasmodium allelic families' distribution in Madagascar.

\section{Conclusion}

The present study highlighted the possibility of performing malaria diagnosis and molecular genetic diversity analysis of Plasmodium using blood samples collected on mRDT as DNA source. Preliminary data from this study showed high genetic diversity of $P$. falciparum populations in Ankazomborona and in Matanga but multiple infection rate was low in the both study sites.

This study provides fundamental information on $P$. falciparum genetic diversity and allow to update available data. The results of this study can be used as a baseline information for future studies on parasite transmission dynamics and to evaluate effectiveness malaria prevention and control strategies.

\section{Declarations}

\section{Acknowledgement}

We are thankful to the technicians and medical team, from National Malaria Control Program, for their technical support. We are grateful to Didier Menard, University of Strasbourg for his precious help and advice.

Authors' contributions: All authors contributed equally to preparing the final version of the manuscript. VA and ER were in charge of analysis and parasite genotyping. AR is guarantor of the paper.

\section{Availability of data and materials}

The data are available from the National Malaria Control Programme of Madagascar.

\section{Ethics approval and consent to participate}

The study was part of malaria surveillance approved by the Ethics Committee of the Ministry of Health of Madagascar (No. 083/MSANP/CE/11-2012).

\section{Consent for publication}

All the authors have agreed to the submission of this manuscript for publication. 


\section{Competing interests}

The authors declare that they have no other conflict of interest.

Funding: This work was supported by The Global Fund.

\section{Author details}

${ }^{1}$ Mention Biochimie Fondamentale et Appliquée, Ecole Doctorale Science de la Vie et de l'Environnement, Faculté des Sciences, Université d'Antananarivo, Madagascar.

${ }^{2}$ Programme National de lutte contre le paludisme, Ministère de la Santé Publique, Antananarivo, Madagascar.

${ }^{3}$ Faculté de Médecine, Université de Fianarantsoa, Madagascar.

${ }^{4}$ Centre National d'Application de Recherche Pharmaceutique, Madagascar.

\section{References}

1. Some AF, Bazie T, Zongo I, Yerbanga RS, Nikiema F, Neya C, Taho LK, Ouedraogo JB: Plasmodium falciparum msp1 and msp2 genetic diversity and allele frequencies in parasites isolated from symptomatic malaria patients in Bobo-Dioulasso, Burkina Faso. Parasit Vectors 2018, 11:323.

2. WHO: World Malaria Report. World Health Organization; 2021.

3. Bhatt S, Weiss DJ, Cameron E, Bisanzio D, Mappin B, Dalrymple U, Battle K, Moyes CL, Henry A, Eckhoff PA, et al: The effect of malaria control on Plasmodium falciparum in Africa between $\mathbf{2 0 0 0}$ and 2015. Nature 2015, 526:207-211.

4. Cnops L, Boderie M, Gillet $P$, Van Esbroeck M, Jacobs J: Rapid diagnostic tests as a source of DNA for Plasmodium species-specific real-time PCR. Malar J 2011, 10:67.

5. Morris U, Aydin-Schmidt B, Shakely D, Martensson A, Jornhagen L, Ali AS, Msellem MI, Petzold M, Gil JP, Ferreira PE, Bjorkman A: Rapid diagnostic tests for molecular surveillance of Plasmodium falciparum malaria -assessment of DNA extraction methods and field applicability. Malar J 2013, 12:106.

6. Veron V, Carme B: Recovery and use of Plasmodium DNA from malaria rapid diagnostic tests. Am J Trop Med Hyg 2006, 74:941-943.

7. Auburn S, Barry AE: Dissecting malaria biology and epidemiology using population genetics and genomics. Int J Parasitol 2017, 47:77-85.

8. Escalante AA, Ferreira MU, Vinetz JM, Volkman SK, Cui L, Gamboa D, Krogstad DJ, Barry AE, Carlton JM, van Eijk AM, et al: Malaria Molecular Epidemiology: Lessons from the International Centers of Excellence for Malaria Research Network. Am J Trop Med Hyg 2015, 93:79-86. 
9. Nabet C, Doumbo S, Jeddi F, Konate S, Manciulli T, Fofana B, L'Ollivier C, Camara A, Moore S, Ranque S, et al: Genetic diversity of Plasmodium falciparum in human malaria cases in Mali. Malar J 2016, 15:353.

10. Nkhoma SC, Nair S, Al-Saai S, Ashley E, McGready R, Phyo AP, Nosten F, Anderson TJ: Population genetic correlates of declining transmission in a human pathogen. Mol Ecol 2013, 22:273-285.

11. Mahdi Abdel Hamid M, Elamin AF, Albsheer MM, Abdalla AA, Mahgoub NS, Mustafa SO, Muneer MS, Amin M: Multiplicity of infection and genetic diversity of Plasmodium falciparum isolates from patients with uncomplicated and severe malaria in Gezira State, Sudan. Parasit Vectors 2016, 9:362.

12. Apinjoh TO, Tata RB, Anchang-Kimbi JK, Chi HF, Fon EM, Mugri RN, Tangoh DA, Nyingchu RV, Ghogomu SM, Nkuo-Akenji T, Achidi EA: Plasmodium falciparum merozoite surface protein 1 block 2 gene polymorphism in field isolates along the slope of mount Cameroon: a cross - sectional study. BMC Infect Dis 2015, 15:309.

13. Cook J, Hergott D, Phiri W, Rivas MR, Bradley J, Segura L, Garcia G, Schwabe C, Kleinschmidt I: Trends in parasite prevalence following 13 years of malaria interventions on Bioko island, Equatorial Guinea: 2004-2016. Malar J 2018, 17:62.

14. Mwingira F, Nkwengulila G, Schoepflin S, Sumari D, Beck HP, Snounou G, Felger I, Olliaro P, Mugittu K: Plasmodium falciparum msp1, msp2 and glurp allele frequency and diversity in sub-Saharan Africa. Malar J 2011, 10:79.

15. Snounou G, Zhu X, Siripoon N, Jarra W, Thaithong S, Brown KN, Viriyakosol S: Biased distribution of msp1 and msp2 allelic variants in Plasmodium falciparum populations in Thailand. Trans $R$ SoC Trop Med Hyg 1999, 93:369-374.

16. Howes RE, Mioramalala SA, Ramiranirina B, Franchard T, Rakotorahalahy AJ, Bisanzio D, Gething PW, Zimmerman PA, Ratsimbasoa A: Contemporary epidemiological overview of malaria in Madagascar: operational utility of reported routine case data for malaria control planning. Malar $J$ 2016, 15:502.

17. Mouchet J, Blanchy S: [Particularities and stratification of malaria in Madagascar]. Sante 1995, 5:386-388.

18. Adjah J, Fiadzoe B, Ayanful-Torgby R, Amoah LE: Seasonal variations in Plasmodium falciparum genetic diversity and multiplicity of infection in asymptomatic children living in southern Ghana. BMC Infect Dis 2018, 18:432.

19. Zhong D, Lo E, Wang X, Yewhalaw D, Zhou G, Atieli HE, Githeko A, Hemming-Schroeder E, Lee MC, Afrane $Y$, Yan G: Multiplicity and molecular epidemiology of Plasmodium vivax and Plasmodium falciparum infections in East Africa. Malar J 2018, 17:185.

20. Snounou G, Viriyakosol S, Zhu XP, Jarra W, Pinheiro L, do Rosario VE, Thaithong S, Brown KN: High sensitivity of detection of human malaria parasites by the use of nested polymerase chain reaction. Mol Biochem Parasitol 1993, 61:315-320.

21. Duah NO, Matrevi SA, Quashie NB, Abuaku B, Koram KA: Genetic diversity of Plasmodium falciparum isolates from uncomplicated malaria cases in Ghana over a decade. Parasit Vectors 2016, 9:416. 
22. Soe TN, Wu Y, Tun MW, Xu X, Hu Y, Ruan Y, Win AYN, Nyunt MH, Mon NCN, Han KT, et al: Genetic diversity of Plasmodium falciparum populations in southeast and western Myanmar. Parasit Vectors 2017, 10:322.

23. Mohammed H, Kassa M, Mekete K, Assefa A, Taye G, Commons RJ: Genetic diversity of the msp-1, msp-2, and glurp genes of Plasmodium falciparum isolates in Northwest Ethiopia. Malar J 2018, 17:386.

24. PNLP: Plan stratégique national de lutte contre le paludisme à Madagascar (2013 - 2017).

Programme National de Lutte contre le Paludisme; 2013.

25. Chen JT, Li J, Zha GC, Huang G, Huang ZX, Xie DD, Zhou X, Mo HT, Eyi JUM, Matesa RA, et al: Genetic diversity and allele frequencies of Plasmodium falciparum msp1 and msp2 in parasite isolates from Bioko Island, Equatorial Guinea. Malar J 2018, 17:458.

26. Niang M, Thiam LG, Loucoubar C, Sow A, Sadio BD, Diallo M, Sall AA, Toure-Balde A: Spatio-temporal analysis of the genetic diversity and complexity of Plasmodium falciparum infections in Kedougou, southeastern Senegal. Parasit Vectors 2017, 10:33.

27. Al-abd NM, Mahdy MA, Al-Mekhlafi AM, Snounou G, Abdul-Majid NB, Al-Mekhlafi HM, Fong MY: The suitability of $\mathrm{P}$. falciparum merozoite surface proteins 1 and 2 as genetic markers for in vivo drug trials in Yemen. PLoS One 2013, 8:e67853.

28. Singana BP, Mayengue PI, Niama RF, Ndounga M: Genetic diversity of Plasmodium falciparum infection among children with uncomplicated malaria living in Pointe-Noire, Republic of Congo. Pan Afr Med J 2019, 32:183.

29. Rakotomanjaka T: Evaluation de l'efficacité de la combination thérapeutique à base d'artesimine ACT : cas de commune Matanga (district de Vangaindrano). Universitéd’Antananarivo, Biochimie, Biodiversité et Santé, Faculté des Sciences; 2016.

30. Randimby Rajaonarisaonina F: Identification des espèces plasmodiales chez les anophèles des marges de haute terre centrale de Madagascar Université d’Antananarivo, Biologie, Ecologie et conservation Animale, Faculté des Sciences; 2012.

31. Razafiarimanga Z: Etude de polymorphisme du gène Msp2 et de microsatellites du génome de Plasmodium falciparum à Saharevo et à Andapa Université d'Antananarivo, Biochimie Appliquée aux Sciences Médicales, Faculté des Sciences; 2005.

32. Raj DK, Das BR, Dash AP, Supakar PC: Genetic diversity in the merozoite surface protein 1 gene of Plasmodium falciparum in different malaria-endemic localities. Am J Trop Med Hyg 2004, 71:285289.

33. Ranjit MR, Sharma YD: Genetic polymorphism of falciparum malaria vaccine candidate antigen genes among field isolates in India. Am J Trop Med Hyg 1999, 61:103-108.

\section{Figures}




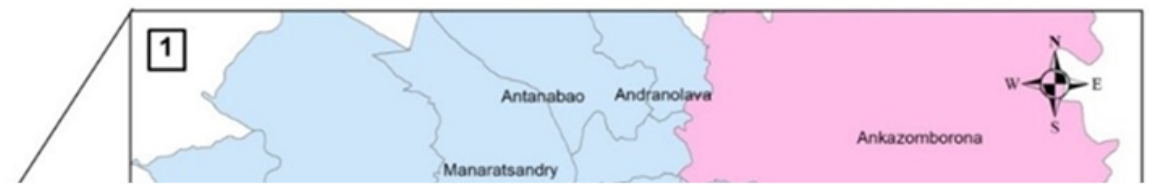

Figure 1

Geographical situation of Ankazomborona and Matanga (Source: BD 500 and FTM)

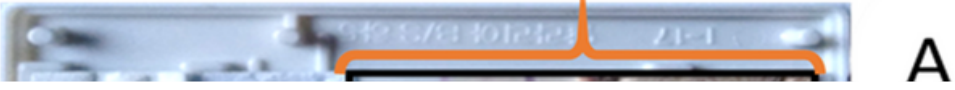

Figure 2 
Fragment sampling of RDT strip

A: Distal part, B: Central part, C: Proximal part, D: All parts

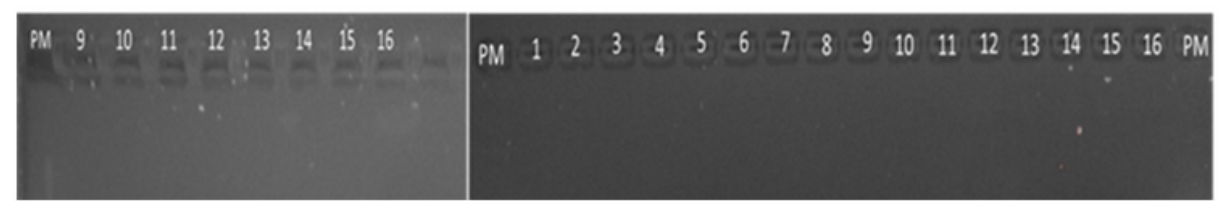

\section{Figure 3}

PCR product from DNA extacted by the two methods: Instagena matrix (1 to 8) and simple elution in water (9 to 16)

Expected size 206 bp for $P$. falciparum (A) and 120 bp for $P$. vivax (B),

PM: 100bp DNA ladder marker, 1 - 16: samples 


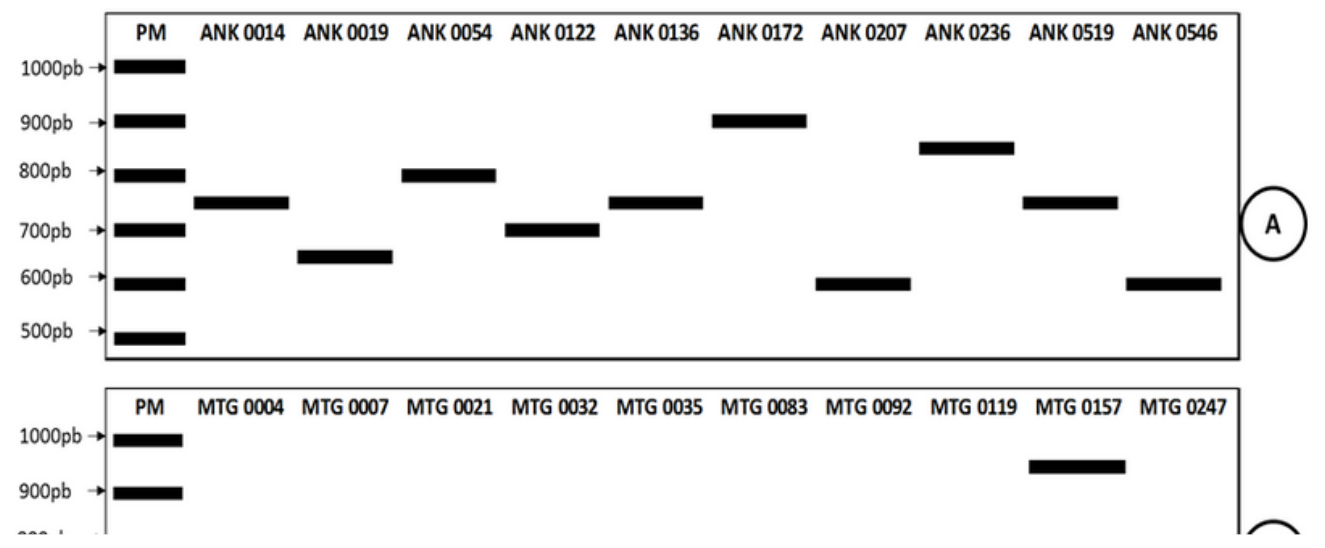

Figure 4

Polymorphism of P. falciparum glurp gene 